Abstract

\title{
In vitro Antioxidant Properties of Bersama abyssinica Stem Bark Extracts ${ }^{\dagger}$
}

\author{
Kouadio Ibrahime Sinan ${ }^{1, *}$, Kouadio Bene ${ }^{2}$, Abdurrahman Aktumsek ${ }^{1}$ and Gokhan Zengin ${ }^{1}$ \\ 1 Department of Biology, Science Faculty, Selcuk University, 42130 Konya, Turkey; \\ aktumsek@selcuk.edu.tr (A.A.); gokhanzengin@selcuk.edu.tr (G.Z.) \\ 2 Laboratoire de Botanique et Phytothérapie, Unité de Formation et de Recherche Sciences de la Nature, \\ Université Nangui Abrogoua, 02 BP 801 Abidjan 02, Abidjan 00225, Côte d'Ivoire; kouadio777@gmail.com \\ * Correspondence: sinankouadio@gmail.com; Tel.: +90-332-232-781 \\ + Presented at the 3rd International conference on Natural Products for Cancer Prevention and Therapy, \\ Kayseri, Turkey, 18-20 December 2019.
}

Published: 26 December 2019

\begin{abstract}
Bersama abyssinica, belonging to the Melianthaceae family, is distributed across Sub Saharan Africa. Decoctions of the bark, leaves, and roots of B. abyssinica have been extensively used in traditional medicine to manage many stomach complications such as colic, diarrhea, dysentery, and intestinal worms. In this study, we examined three extracts (ethyl acetate, methanol and water) obtained from B. abyssinica stem barks in terms of antioxidant properties. The antioxidant abilities were investigated by different chemical methods, including free radical scavenging (DPPH and ABTS), reducing power (CUPRAC and FRAP), metal chelating and phosphomolybdenum assay. In addition, total phenolic and flavonoid contents in the extracts were calculated. The highest level of phenolics was determined in water extract ( $230.83 \mathrm{mg} \mathrm{GAE} / \mathrm{g}$ extract), followed by methanol (216.79 mg GAE/g extract) and ethyl acetate (100.57 mg GAE/g extract). In same line with total phenolic content, the best antioxidant properties were noted for water and methanol extracts. Our findings suggested that B. abyssinica stem bark extracts could be considered as promising sources of natural antioxidants.
\end{abstract}

Keywords: Bersama; antioxidant; free radicals; phenolic

(C) 2019 by the authors. Licensee MDPI, Basel, Switzerland. This article is an open access article distributed under the terms and conditions of the Creative Commons Attribution (CC BY) license (http://creativecommons.org/licenses/by/4.0/). 